\title{
Impact of Comorbidities on Survival Among Patients with Chronic Myeloid Leukaemia Using the Charlson Comorbidity Index Retrospective study from Basra, Iraq

$$
\begin{aligned}
& \text { تأثير الأمراض المصاحبة على البقاء على قيد الحياة بين مرضى سرطان الدم }
\end{aligned}
$$

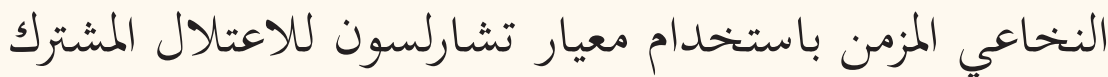

$$
\begin{aligned}
& \text { دراسة استعادية من البصرة، العراق }
\end{aligned}
$$

$$
\text { رافد عَبُود، حسُون حسُون، أسعد خلف، إيلاف صالح }
$$

\begin{abstract}
Objectives: In chronic diseases, comorbidities are known to have a strong negative association with overall survival (OS). This study aimed to use the Charlson Comorbidity Index (CCI) to examine the effect of comorbidities on OS among patients with chronic myeloid leukaemia (CML) treated with tyrosine kinase inhibitors. Methods: This retrospective study was conducted between January 2006 and October 2016 and included 247 CML patients treated at the Basra Oncology \& Haematology Centre, Basra, Iraq. Information from hospital records was used to calculate CCI scores and patients were divided into groups based on scores of 2-3 (CCI1 group) or $\geq 4$ (CCI2 group). The OS was calculated using Kaplan-Meier curves. Results: There were 177 (71.7\%) patients in the CCI1 group and 70 (28.3\%) in the CCI2 group. Overall, patients in the CCI1 group were significantly younger compared to those in the CCI2 group (median age: 35 versus 60 years; $P<0.001$ ); however, the gender distribution was similar in both groups (male-to-female ratio of 1:1.06 versus 1:1.18, respectively; $P=0.683$ ). Diabetes mellitus was the most common comorbidity $(17 \%)$, followed by hypertension (12\%) and gastrointestinal diseases $(6 \%)$. There were no significant differences in mortality between the groups $(9.6 \%$ versus $8.6 \% ; P=0.801$ ). In total, $69.6 \%$ of all deaths were related to CML progression rather than to the presence of comorbidities. Conclusion: No significant correlation was found between CCI score and OS among CML patients in Basra. However, larger long-term prospective studies are needed to evaluate associations with median age at diagnosis and disease severity and to develop region-specific prognostic scales.
\end{abstract}

Keywords: Comorbidity; Chronic Myeloid Leukemia; Mortality; Survival Analysis; Chronic Diseases; Iraq.

الملخص: الهدف: من المعروف أنه في الأمراض المزمنة يكون للأمراض المصاحبة ارتباط سلبي قوي مع البقاء على قيد الحئ الحياة بشكل

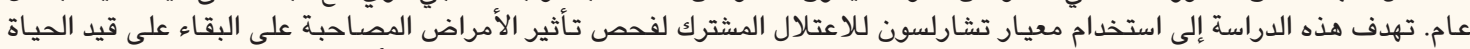

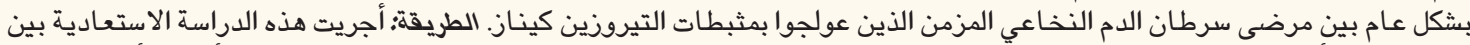

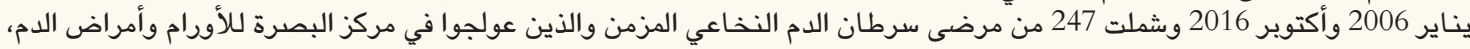

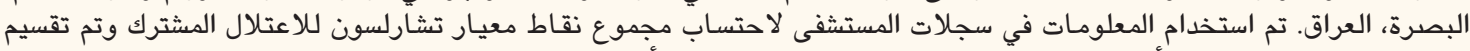

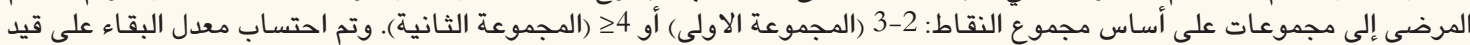

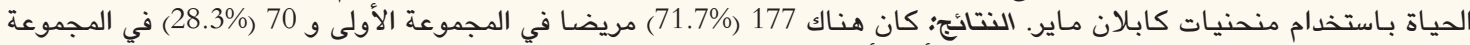

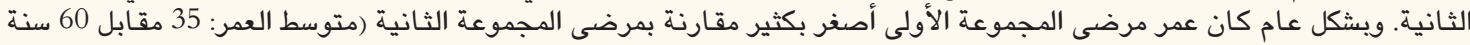

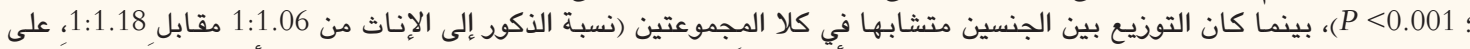

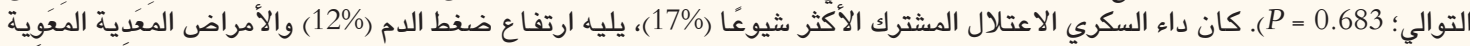

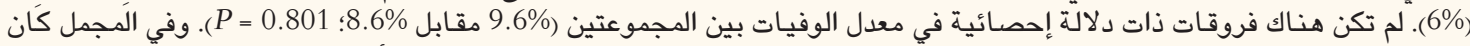

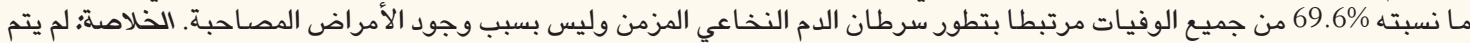

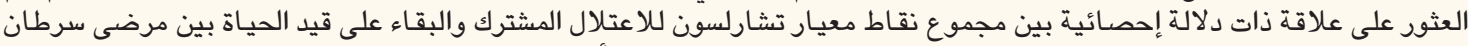

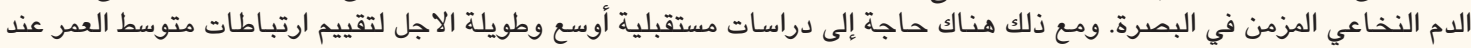

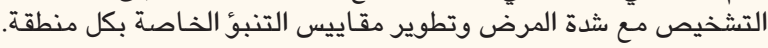

الكلمات المفتاحية: الاعتلال المشترك؛ سرطان الدم النخاعي المزمن؛ وفيات؛ تدليل البقاء على قيد الحياة؛ الأمراض المزمنة؛ العراق.

\section{AdVANCES IN KNOWLeDge}

The median age of patients with chronic myeloid leukaemia (CML) in Basra, Iraq, was lower compared to those reported in Western countries.

The majority of deaths were attributable to disease progression, rather than the presence of comorbidities. 
Larger prospective studies are needed to confirm the findings of the current study and to evaluate the potential role of comorbidity treatment on survival. Such data may help in the development of region-specific prognostic scales.

\section{Application to Patient Care}

There is no decrease in overall survival due to the presence of comorbidities among chronic myeloid leukaemia patients in Basra, Iraq, and patients may present at a younger age in comparison to those in Western countries.

$\mathrm{W}$ ORLDWIDE, CHRONIC MYELOID LEUKAEMIA (CML) accounts for approximately $15 \%$ of all types of leukaemia in adults. ${ }^{1}$ Although there is paucity of epidemiological data, the incidence of CML is usually considered similar across the globe. ${ }^{2,3}$ Studies from North America and Europe have reported an age-adjusted incidence of 0.6-2 and 0.7-1 per 100,000 individuals, respectively.,3 However, in Iraq, the age-standardised incidence of leukaemia has been reported as 3.9-4.3 per 100,000 individuals.5,6 The varying prevalence and mortality rates of $\mathrm{CML}$ may be due to differences in accessibility to treatment options; for example, the availability of tyrosine kinase inhibitors (TKIs) has significantly decreased annual CML-related mortality rates to $<2-3 \%{ }^{2,7}$ Ironically, however, this decrease in mortality has increased the prevalence of CML worldwide. ${ }^{2,3,8}$

Comorbidities are defined as distinct additional clinical conditions that either pre-exist or occur during the course of a primary disease. ${ }^{9}$ Comorbidities have a strong negative association with overall survival (OS) among patients with chronic diseases; for example, in cancer patients, comorbidities can affect the diagnosis, treatment and outcomes..$^{10}$ Comorbidities can also increase the cost of treatment and decrease the patient's quality of life. ${ }^{11}$ The presence of comorbidities has been shown to influence OS in chronic lymphocytic leukaemia (CLL). ${ }^{10,12}$ Similarly, comorbidities have also been reported to have a negative impact on OS among CML patients; however, there is no effect on treatment success with TKIs. ${ }^{13,14}$

The impact of comorbidities on disease outcomes can be measured by a well-established and validated 20-item risk-scoring tool, the Charlson Comorbidity Index (CCI). ${ }^{15,16}$ This tool is based on the principle that age and the presence and severity of comorbidities increase the likelihood of mortality among patients who receive treatment for chronic illnesses. Scores for each item range from 1-6, with the maximum score given in the presence of a metastatic tumour or acquired immune deficiency syndrome; age is also considered a risk factor, with an additional point for each completed decade beyond 40 years. ${ }^{15}$

To the best of the authors' knowledge, the use of prognostic scales such as the CCI has not been adequately studied among CML patients in Iraq and other Middle Eastern countries. This study aimed to evaluate the effect of comorbidities and age on OS among patients with CML treated with imatinib or other TKIs using the CCI.

\section{Methods}

This retrospective study was conducted between January 2006 and October 2016 at the Basra Oncology \& Haematology Centre, Basra, Iraq. A total of $285 \mathrm{CML}$ cases registered at the Basra Oncology \& Haematology Centre during the study period were reviewed. Only CML patients treated with TKIs and who underwent regular follow-up were enrolled in the study $(\mathrm{N}=247)$. Patients who discontinued treatment for over three months continuously (including pregnant women) and those who did not have regular follow-up visits during the study period were excluded at the time of screening.

The clinical and demographic information necessary to calculate CCI scores were extracted from the patients' hospital records, including age, gender, date of diagnosis, duration of treatment, outcome and cause of death. The medical records also included a detailed patient history and results of a physical examination in addition to the initial CCI score, an essential part of early assessment for every patient prior to receiving therapy. The overall CCI scores were calculated according to Table $1 .{ }^{15}$ Based on their scores, patients were divided into two groups; those with scores of 2-3 were assigned to the CCI1 group, while patients with higher scores of $\geq 4$ were allocated to the CCI2 group.

In cases where patients had a history of past illnesses that fell within the CCI parameters (i.e. aortic aneurysms of $\geq 6 \mathrm{~cm}$, dementia, chronic pulmonary disease or peptic ulcer disease), the previous diagnosis and management of the illness was reviewed with relevant specialists, if necessary. In order to evaluate the molecular response to TKI treatment, patients underwent regular breakpoint cluster region-Abelson murine leukaemia screening every six months using the GeneXpert $^{\circledR}$ assay (Cepheid Inc., Sunnyvale, California, USA). In order to avoid bias, the analyst was blinded to the patient details.

The statistical analysis was conducted using Epi Info ${ }^{\mathrm{TM}}$ software, Version 3.3 (Centers for Disease Control and Prevention, Atlanta, Georgia, USA). The 
cause of death was evaluated and recorded individually for each patient while the mortality rate was calculated for the overall study population. For the purposes of the study, OS was defined as the time between diagnosis and death, irrespective of the administration of TKIs. The OS probabilities were calculated using KaplanMeier curves. A $P$ value of $<0.05$ was considered statistically significant.

This study was reviewed and approved by the Medicine Ethical Committee of Basra College of Medicine, Basra, Iraq (\#569). All procedures and protocols involved in this study were conducted in accordance with the principles of the revised Declaration of Helsinki.

Table 1: Weighted scores for each item of the 20-item Charlson Comorbidity Index ${ }^{15}$

\begin{tabular}{|c|c|}
\hline Item & Weighting \\
\hline 1. Age & $\begin{array}{l}\text { Score of } 1 \text { for every } \\
\text { decade over } 40 \\
\text { years of age }\end{array}$ \\
\hline \multicolumn{2}{|l|}{$\begin{array}{l}\text { 2. History of myocardial infarct (not } \\
\text { ECG changes alone) }\end{array}$} \\
\hline \multicolumn{2}{|l|}{ 3. Congestive heart failure } \\
\hline \multicolumn{2}{|l|}{$\begin{array}{l}\text { 4. Peripheral vascular disease } \\
\text { including aortic aneurysms of } \geq 6 \mathrm{~cm}\end{array}$} \\
\hline \multicolumn{2}{|l|}{$\begin{array}{l}\text { 5. Cerebrovascular disease (i.e. } \\
\text { accident with mild or no residual } \\
\text { impact or a transient ischaemic } \\
\text { attack) }\end{array}$} \\
\hline 6. Dementia & Score of 1 per item \\
\hline \multicolumn{2}{|l|}{ 7. Chronic pulmonary disease } \\
\hline \multicolumn{2}{|l|}{ 8. Connective tissue disease } \\
\hline \multicolumn{2}{|l|}{ 9. Peptic ulcer disease } \\
\hline \multicolumn{2}{|l|}{$\begin{array}{l}\text { 10. Mild liver disease without portal } \\
\text { hypertension and including chronic } \\
\text { hepatitis }\end{array}$} \\
\hline \multicolumn{2}{|l|}{$\begin{array}{l}\text { 11. Diabetes without end-organ } \\
\text { damage (excluded in patients on } \\
\text { dietary control alone) }\end{array}$} \\
\hline \multicolumn{2}{|l|}{ 12. Haemiplegia } \\
\hline \multicolumn{2}{|l|}{ 13. Moderate or severe renal disease } \\
\hline $\begin{array}{l}\text { 14. Diabetes with end-organ damage } \\
\text { (i.e. retinopathy, neuropathy, } \\
\text { nephropathy or brittle diabetes) }\end{array}$ & Score of 2 per item \\
\hline \multicolumn{2}{|l|}{$\begin{array}{l}\text { 15. Tumour without metastasis } \\
\text { (excluded if }>5 \text { years since diagnosis) }\end{array}$} \\
\hline \multicolumn{2}{|l|}{ 16. Leukaemia (acute or chronic) } \\
\hline \multicolumn{2}{|l|}{ 17. Lymphoma } \\
\hline 18. Moderate or severe liver disease & Score of 3 \\
\hline \multicolumn{2}{|l|}{ 19. Metastatic tumour } \\
\hline $\begin{array}{l}\text { 20. Acquired immune deficiency } \\
\text { syndrome }\end{array}$ & Score of 6 per item \\
\hline
\end{tabular}

\section{Results}

A total of 285 CML cases were registered at the Basra Oncology \& Haematology Centre during the study period; of these, 247 (86.7\%) patients treated with TKIs and followed-up regularly were included in the analysis. The median age of these patients was 43.5 years (range: $5-102$ years old) and the male-to-female ratio was 1:1.09 [Table 2]. Based on their CCI scores, 177 (71.7\%) patients were allocated to the CCI1 group (i.e. those with lower CCI scores) and 70 (28.3\%) to the CCI2 group (i.e. those with higher CCI scores). Patients in the CCI1 group were considerably younger than those in the CCI2 group (median age: 35 versus 60 years; $P<0.001)$. However, the gender distribution was similar in both groups (male-to-female ratio of 1:1.06 versus $1: 1.18 ; P=0.683$ ) [Table 3].

The median duration of follow-up was 50 months (range: 2-198 months). The most common comorbidity was diabetes mellitus (17\%), followed by hypertension (12\%) and gastrointestinal disorders (6\%). The least common comorbidities were hepatitis, neurological disorders and other cancers (1\% each) [Figure 1]. Almost all (94\%) of the patients were initially prescribed $400 \mathrm{mg}$ of imatinib; however, 88 (38\%) of which were later switched to $800 \mathrm{mg}$ of nilotinib. In contrast,

Table 2: Age and gender distribution of patients with chronic myeloid leukaemia in Basra, Iraq ( $=247)$

\begin{tabular}{lcccc}
$\begin{array}{l}\text { Age } \\
\text { in } \\
\text { years }\end{array}$ & $\begin{array}{c}\text { Male } \\
(\mathbf{n}=118)\end{array}$ & $\begin{array}{c}\text { Female } \\
(\mathbf{n}=129)\end{array}$ & Total & $\begin{array}{c}\text { Cumulative } \\
\text { percentage }\end{array}$ \\
\hline 10 & $2(1.7)$ & $2(1.6)$ & $4(1.6)$ & 1.6 \\
$10-19$ & $8(6.8)$ & $6(4.7)$ & $14(5.7)$ & 7.3 \\
$20-29$ & $18(15.3)$ & $15(11.6)$ & $33(13.4)$ & 20.6 \\
$30-39$ & $24(20.3)$ & $29(22.5)$ & $53(21.5)$ & 42.1 \\
$40-49$ & $20(16.9)$ & $25(19.4)$ & $45(18.2)$ & 60.3 \\
$50-59$ & $29(24.6)$ & $27(20.9)$ & $56(22.7)$ & 83 \\
$\geq 60$ & $17(14.4)$ & $25(19.4)$ & $42(17)$ & 100
\end{tabular}

Table 3: Age and gender distribution according to comorbidity groups of patients with chronic myeloid leukaemia in Basra, Iraq $(\mathrm{N}=247)$

\begin{tabular}{|c|c|c|c|c|}
\hline \multirow[t]{2}{*}{ Characteristic } & \multirow[t]{2}{*}{ Total } & \multicolumn{2}{|c|}{ Group* } & \multirow{2}{*}{$\begin{array}{c}P \\
\text { value }\end{array}$} \\
\hline & & $\begin{array}{c}\text { CCI1 } \\
(n=177)\end{array}$ & $\begin{array}{c}\text { CCI2 } \\
(n=70)\end{array}$ & \\
\hline $\begin{array}{l}\text { Median age in } \\
\text { years (range) }\end{array}$ & $\begin{array}{c}43.5 \\
(5-102)\end{array}$ & $\begin{array}{c}35 \\
(5-59)\end{array}$ & $\begin{array}{c}60 \\
(37-102)\end{array}$ & $<0.001$ \\
\hline $\begin{array}{l}\text { Male-to-female } \\
\text { ratio }\end{array}$ & 1:1.09 & $1: 1.06$ & $1: 1.18$ & 0.683 \\
\hline
\end{tabular}




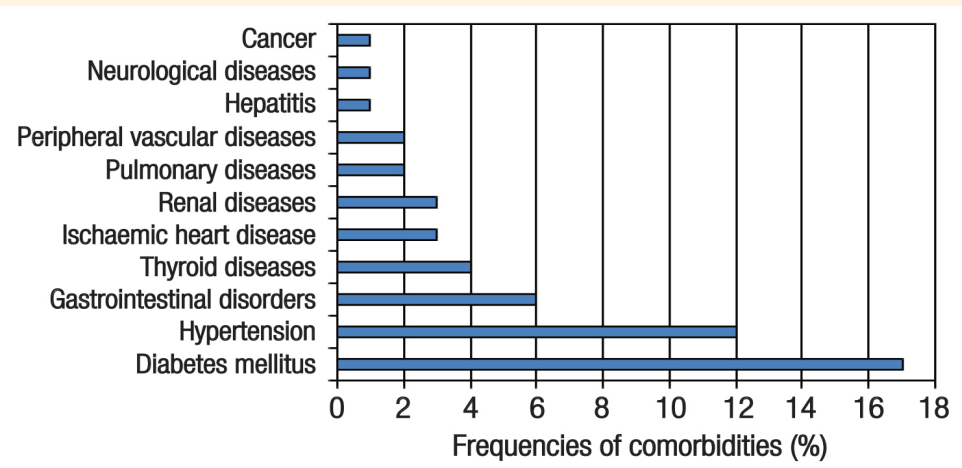

Figure 1: Frequency of comorbidities among patients with chronic myeloid leukaemia in Basra, Iraq ( $\mathrm{N}=247)$.

Table 4: Mortality rate according to comorbidity groups among patients with chronic myeloid leukaemia in Basra, Iraq $(\mathrm{N}=247)$

\begin{tabular}{|c|c|c|c|c|c|c|}
\hline \multirow[t]{3}{*}{ Group* } & \multicolumn{6}{|c|}{ n (\%) } \\
\hline & \multicolumn{3}{|c|}{ Dead } & \multicolumn{3}{|c|}{ Alive } \\
\hline & Total & Male & Female & Total & Male & Female \\
\hline $\begin{array}{l}\text { CCI1 } \\
(\mathrm{n}=177)\end{array}$ & $\begin{array}{c}17 \\
(9.6)\end{array}$ & $\begin{array}{c}9 \\
(5.1)\end{array}$ & $\begin{array}{c}8 \\
(4.5)\end{array}$ & $\begin{array}{c}160 \\
(90.4)\end{array}$ & $\begin{array}{c}77 \\
(43.5)\end{array}$ & $\begin{array}{c}83 \\
(46.9)\end{array}$ \\
\hline $\begin{array}{l}\mathrm{CCI} 2 \\
(\mathrm{n}=70)\end{array}$ & $\begin{array}{c}6 \\
(8.6)\end{array}$ & $\begin{array}{c}3 \\
(4.3)\end{array}$ & $\begin{array}{c}3 \\
(4.3)\end{array}$ & $\begin{array}{c}64 \\
(91.4)\end{array}$ & $\begin{array}{c}29 \\
(41.4)\end{array}$ & $\begin{array}{l}35 \\
(50)\end{array}$ \\
\hline Total & $\begin{array}{c}23 \\
(9.3)\end{array}$ & $\begin{array}{c}12 \\
(4.9)\end{array}$ & $\begin{array}{c}11 \\
(4.5)\end{array}$ & $\begin{array}{c}224 \\
(90.7)\end{array}$ & $\begin{array}{c}106 \\
(42.9)\end{array}$ & $\begin{array}{c}118 \\
(47.8)\end{array}$ \\
\hline
\end{tabular}

$C C I=$ Charlson Comorbidity Index .

*As assessed using the Charlson Comorbidity Index, with patients receiving scores of 2-3 or $\geq 4$ assigned to the CCI1 and CCI2 groups, respectively. ${ }^{15}$

15 patients who were initially administered nilotinib continued taking it throughout the study period. Overall, $55.7 \%$ of patients responded to treatment; however, $14.9 \%$ had suboptimal results and $29.4 \%$ failed to respond at all.

A total of 23 patients died during the study period, resulting in a mortality rate of $9.3 \%$. The median age of those who died was 44 years, while the median age of those who survived was 43 years. Mortality rates were similar for patients of both genders and across both CCI1 and CCI2 groups [Table 4]. There was no significant difference in mortality according to the CCI score $(9.6 \%$ versus $8.6 \% ; P=0.801)$. Of the 23 deaths, analysis showed that $69.6 \%$ were related to CML progression, rather than comorbidity burden. The remaining $30.4 \%$ of deaths were due to ischaemic heart disease $(8.7 \%)$, other cancers $(8.7 \%$; including one case each of transitional cell carcinoma of the bladder and laryngeal cancer), renal failure (4.3\%), a cerebrovascular-related accident (4.3\%) and a war injury (4.3\%). Figure 2 shows the Kaplan-Meier cumulative survival curve for the two groups across the follow-up period.

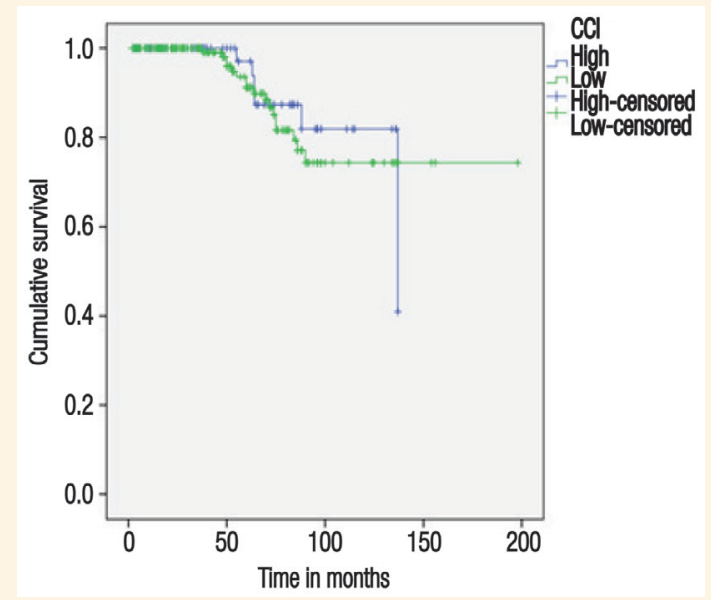

Figure 2: Kaplan-Meier survival curve showing cumulative survival according to comorbidity groups" among patients with chronic myeloid leukaemia in Basra, $\operatorname{Iraq}(\mathrm{N}=247)$. $C C I=$ Charlson Comorbidity Index .

*As assessed using the Charlson Comorbidity Index, with patients receiving scores of $2-3$ or $\geq 4$ assigned to the CCI1 and CCI2 groups, respectively. ${ }^{15}$

\section{Discussion}

The CCI tool assesses the presence and severity of various comorbidities as parameters in the prognostic analysis of chronic diseases and has been utilised successfully among patients with a variety of illnesses, including CML, CLL and myelodysplastic syndrome. ${ }^{10,12,13,15}$ Among CML patients, clinical studies have utilised the CCI to evaluate the effect of comorbidities on OS, event-free survival, remission rates, progression of the disease to accelerated phase or blast crisis, onset of complications, compliance to treatment and all-cause or cancer-specific mortality rates. ${ }^{13,14,17-21}$ In CML, most previous studies have evaluated the association between CCI and survival outcomes in patients being treated with imatinib; however, Breccia et al. reported its use among those treated with other TKIs (i.e. dasatinib). ${ }^{13,14,17-21}$ 
As the availability of TKIs has markedly decreased mortality rates among CML patients, appropriate information regarding risk factors or poor prognostic markers can help in the individualisation of therapy? As such, findings from the present study may be helpful as a basis for the development of a modified risk assessment system for patients with CML in Iraq. Use of an appropriate prognostic scale can help in the appropriate selection of TKIs, proper monitoring during treatment and assessment of survival outcomes and treatment response among affected patients. ${ }^{7}$

In the present study, the median age of CML patients at the time of diagnosis was 43.5 years; this is younger in comparison to patients reported in Western populations. ${ }^{13,14,17}$ Similar findings have been reported in other Iraqi epidemiological studies; however, unlike the current study, these previous reports described CML as being more common among males than females. ${ }^{22,23}$ As the median age of the patient population was younger in the present study, CCI scoring was ageadjusted for assessment purposes. As with previous studies from other countries, diabetes was found to be the most common comorbidity reported among CML patients in the current study. ${ }^{13,14,17,20}$

Previous research suggests that higher CCI scores are significantly associated with lower OS probabilities, with inverse associations noted between CCI scores and OS among chronic phase CML patients in Japan, Italy and Germany. ${ }^{13,14,19}$ Saussele et al. observed that higher CCI scores were significantly associated with lower OS probabilities $(P<0.001)$, even after excluding age from the CCI calculation. ${ }^{13}$ The presence of comorbidities at the time of diagnosis has also been associated with poor survival outcomes among CML patients being treated with TKIs, with comorbidities having more impact on survival than the disease itself. ${ }^{12}$ Similarly, Imataki et al. documented a significant logrank association between comorbidity at diagnosis and survival among CML patients on TKI treatment $(P=0.0136) .{ }^{20}$ Breccia et al. also reported that comorbidities had a similar impact on median OS and nonCML-related deaths. ${ }^{19}$

In contrast, the present retrospective analysis did not reveal a significant difference in mortality rates among CML patients according to CCI scores. Instead, the study found that $69.6 \%$ of deaths in the patient population were due to CML and not the presence or severity of comorbidities. This was in contrast to the findings of Saussele et al. and Uemura et al., who reported that mortality among CML patients was more dependent on comorbidities than CML. ${ }^{13,14}$ This difference in findings may be because of the more aggressive behaviour of CML among the Iraqi people. As such, mutational studies are recommended for
Iraqi patients with primary and secondary failure to investigate the nature of CML in this population.

Other prognostic scales available for use among CML patients include the Sokal Index, Hasford Risk Score, Karnofsky Performance Scale Index (KPSI) and the European Treatment and Outcome Study (EUTOS) score. ${ }^{24-26}$ It is likely that varying results regarding OS in CML patients reported by different studies is due to the selection of disparate prognostic markers and scoring systems, thereby highlighting the need for a uniform prognostic scoring system for CML patients. Of the CCI, EUTOS and KPSI scales, Saussele et al. found that CCI was the most powerful predictor for OS in German patients with CML. ${ }^{13}$ Similarly, the authors of the current study plan to compare the aforementioned prognostic scores among CML patients being treated with TKIs at the Basra Oncology \& Haematology Centre. Additionally, further research evaluating the application of the CCI tool among older patients is necessary.

The limitations of the current study include its retrospective design, the limited sample size and the lack of availability of data regarding management of the comorbidities identified in the study population. Although there was no correlation between CCI and OS, further analysis using a larger dataset is needed to generate stronger evidence for this finding. Additionally, future studies should investigate the correlation between age at disease onset and patient outcome.

\section{Conclusion}

The median age of CML patients in Basra was lower than epidemiological data reported from other countries. Moreover, the CCI score was not significantly associated with OS; for the majority of patients, disease progression due to CML itself was the cause of death, rather than the presence or severity of comorbidities. Further research into the development of more accurate region-specific prognostic scoring systems to evaluate risk-based outcomes among CML patients would facilitate individualised treatment for this population.

\section{CONFLICT OF INTEREST}

The authors declare no conflicts of interest.

\section{FUNDING}

No funding was received for this study.

\section{References}

1. Djouadi K, Abdennebi N, Harieche F, Nacer RA, Hamladji RM, Bouchakour A, et al. Epidemiological approach of chronic myeloid leukemia: Algerian-Tunisian study. Blood 2016; 128:5440. 
2. World Health Organization. Chronic myelogenous leukemia: Union for International Cancer Control 2014 review of cancer medicines on the WHO list of essential medicines. From: www.who.int/selection_medicines/committees/expert/20/ applications/CML.pdf Accessed: Feb 2019.

3. Höglund M, Sandin F, Simonsson B. Epidemiology of chronic myeloid leukaemia: An update. Ann Hematol 2015; 94:S241-7. https://doi.org/10.1007/s00277-015-2314-2.

4. Rohrbacher M, Hasford J. Epidemiology of chronic myeloid leukaemia (CML). Best Pract Res Clin Haematol 2009; 22:295-302. https://doi.org/10.1016/j.beha.2009.07.007.

5. Hussain RA, Habib OS. Incidence of cancer in Basrah: Results of a household survey. Asian Pac J Cancer Prev 2015; 16:163-7. https://doi.org/10.7314/apjcp.2015.16.1.163.

6. Habib OS, Khalaf AAA, Hasan JG, Alrudainy LA, Hasson HM, Salih HM, et al. Pattern of leukaemia in Basrah. Ann Coll Med Mosul 2013; 39:154-9. https://doi.org/10.33899/mmed.2 013.81277.

7. Huang X, Cortes J, Kantarjian H. Estimations of the increasing prevalence and plateau prevalence of chronic myeloid leukemia in the era of tyrosine kinase inhibitor therapy. Cancer 2012; 118:3123-7. https://doi.org/10.1002/cncr.26679.

8. Cortes JE, Silver RT, Khoury HJ, Kantarjian HM. Chronic myeloid leukemia. From: www.cancernetwork.com/chronic-myeloid-leukemia/chronic-myeloid-leukemia Accessed: Feb 2019.

9. Feinstein AR. The pre-therapeutic classification of co-morbidity in chronic disease. J Chronic Dis 1970; 23:455-68. https://doi. org/10.1016/0021-9681(70)90054-8.

10. Goede V, Cramer P, Busch R, Bergmann M, Stauch M, Hopfinger G, et al. Interactions between comorbidity and treatment of chronic lymphocytic leukemia: Results of German Chronic Lymphocytic Leukemia Study Group trials. Haematologica 2014; 99:1095-100. https://doi.org/10.3324/haematol.2013.096792.

11. Sarfati D, Koczwara B, Jackson C. The impact of comorbidity on cancer and its treatment. CA Cancer J Clin 2016; 66:337-50. https://doi.org/10.3322/caac.21342.

12. Wang R, Gross CP, Halene S, Ma X. Comorbidities and survival in a large cohort of patients with newly diagnosed myelodysplastic syndromes. Leuk Res 2009; 33:1594-8. https://doi.org/10.1016/ j.leukres.2009.02.005.

13. Saussele S, Krauss MP, Hehlmann R, Lauseker M, Proetel U, Kalmanti L, et al. Impact of comorbidities on overall survival in patients with chronic myeloid leukemia: Results of the randomized CML study IV. Blood 2015; 126:42-9. https://doi. org/10.1182/blood-2015-01-617993.

14. Uemura M, Imataki O, Kawachi Y, Kawakami K, Hoshijima Y, Matsuoka A, et al. Charlson Comorbidity Index predicts poor outcome in CML patients treated with tyrosine kinase inhibitor. Int J Hematol 2016; 104:621-7. https://doi.org/10.1007/s12185016-2074-3

15. Charlson M, Szatrowski TP, Peterson J, Gold J. Validation of a combined comorbidity index. J Clin Epidemiol 1994; 47:1245-51. https://doi.org/10.1016/0895-4356(94)90129-5.
16. Charlson ME, Pompei P, Ales KL, MacKenzie CR. A new method of classifying prognostic comorbidity in longitudinal studies: Development and validation. J Chronic Dis 1987; 40:373-83. https://doi.org/10.1016/0021-9681(87)90171-8.

17. Breccia M, Molica M, Colafigli G, Zacheo I, Latagliata R, Tafuri A, et al. Correlation between Charlson Comorbidity Index and outcome in patients with chronic phase chronic myeloid leukemia treated with second-generation tyrosine kinase inhibitors upfront. Leuk Lymphoma 2015; 56:2206-7. https://doi.org/10.3 109/10428194.2014.993391.

18. Breccia M, Latagliata R, Stagno F, Luciano L, Gozzini A, Castagnetti F, et al. Charlson Comorbidity Index and adult comorbidity evaluation-27 scores might predict treatment compliance and development of pleural effusions in elderly patients with chronic myeloid leukemia treated with second-line dasatinib. Haematologica 2011; 96:1457-61. https://doi.org/10.3324/haem atol.2011.041251.

19. Breccia M, Luciano L, Latagliata R, Castagnetti F, Ferrero D, Cavazzini F, et al. Age influences initial dose and compliance to imatinib in chronic myeloid leukemia elderly patients but concomitant comorbidities appear to influence overall and event-free survival. Leuk Res 2014; 38:1173-6. https://doi. org/10.1016/j.leukres.2014.06.020.

20. Imataki O, Uchida S, Oku M, Yokokura S, Uemura M, Kadowaki N. The Charlson Comorbidity Index predicts survival following tyrosine kinase inhibitor treatment in chronic myeloid leukemia patients. Blood 2015; 126:5146.

21. Iurlo A, Ubertis A, Artuso S, Bucelli C, Radice T, Zappa M, et al. Comorbidities and polypharmacy impact on complete cytogenetic response in chronic myeloid leukaemia elderly patients. Eur J Intern Med 2014; 25:63-6. https://doi.org/10.1 016/j.ejim.2013.11.002

22. Hasan KM. Evaluation of chronic myeloid leukemia patients and their molecular responses to tyrosine kinase inhibitors in Erbil City, Iraq. Iraqi J Hematol 2018; 7:1-7. https://doi. org/10.4103/ijh.ijh_28_17.

23. Alameri A, Al-khudhair M, Batool G, Al-Mudhafer A, Murad N Epidemiology of chronic myeloid leukemia in Iraqi patients. In: 14th Congress Of The European Hematology Association, Berlin, Germany, June 4-7, 2009. Haematologica 2009; 94:S578.

24. Sokal JE, Cox EB, Baccarani M, Tura S, Gomez GA, Robertson JE, et al. Prognostic discrimination in "good-risk" chronic granulocytic leukemia. Blood 1984; 63:789-99.

25. Hasford J, Pfirrmann M, Hehlmann R, Allan NC, Baccarani M, Kluin-Nelemans JC, et al. A new prognostic score for survival of patients with chronic myeloid leukemia treated with interferon alfa: Writing Committee for the Collaborative CML Prognostic Factors Project Group. J Natl Cancer Inst 1998; 90:850-8. https://doi.org/10.1093/jnci/90.11.850.

26. Hasford J, Baccarani M, Hoffmann V, Guilhot J, Saussele S, Rosti G, et al. Predicting complete cytogenetic response and subsequent progression-free survival in 2060 patients with CML on imatinib treatment: The EUTOS score. Blood 2011; 118:686-92. https://doi.org/10.1182/blood-2010-12-319038. 